\title{
Chapter 1 \\ Who Can Know My Self? A New Look into Psychological Inquiries Into the Self
}

Mina: And where [we] visited long ago, when [I was] a baby?

Mother: When [you were] a baby, Umeno Park.

Mina: Yeah, right. Was Mina cute as a baby?

Mother: So cute.

(From a conversation between Mina and her mother recorded during a car ride. Mina is 4 years and 6 months old. See Excerpt 1.1 and Chap. 3 for details of data collection and transcription.)

In our everyday lives, we keep constructing the meaning of our experiences and ourselves. Daily conversation, as we see above, is one example. In the episode above, a young girl, Mina, and her mother are reminiscing about their visit to a park. They discuss Mina in the past, with the young girl suggesting to her mother that she, Mina, was a cute baby. It is a suggestion concerning who Mina was in the past, and it is achieved through a series of exchanges about their past. We can observe here the construction of Mina's self-representation through an interaction. However, does the self only emerge in such straightforward descriptions of ourselves? Considering the succession of exchanges in the conversation we experience, the self is not what appears suddenly when we mention ourselves but rather what is constantly under construction throughout the process, and the description of ourselves is only a part of this process.

Regarding this fundamental understanding about the self as it appears in the interactions in which we participate, in this monograph I strive to formulate a new perspective on the self with support from theories that indicate the nature of our minds and meaning construction. In this theoretical framework, children's selves are not the results of forced reflection as posed by researchers. Direct questions to children or adults do not lead to reporting about the self-rather, these questions reveal their thinking about what the self might be. On the other hand, this is the point at which the "psychologists" fallacy" described by James (1890) occurs-we often confuse what we understand and what we are going to describe as functions of the minds of study participants.

Instead, we can observe the self as it emerges when children attempt to reconstruct and present their experiences and their expectations for the future. 
This is also the self we, researchers or observers, find out investigating the interactions in which children participate, because the researchers' positions for interpreting children's conduct must not be hidden or ignored. With this primary orientation, I pay attention to the dynamicity of how children's selves emerge, which cannot be grasped by approaches based on the epistemological position of most psychological research.

Further, when we look at interaction in natural settings, another point of inquiry is how and why it occurs in our lives. For this question, I attempt to inquire into various real-life situations where some dialectic tensions work to promote development, both at micro and macro levels. Thus, the discussion hereafter is an endeavor to understand the self in the midst of the real world, not in the virtual field consisting of researchers' intentions.

\section{We Construct Meaning to Live on: Facing the Future}

Although we do not care about mundane activities in our very ordinary lives and soon forget what we have done, we are always recognizing what we experience and finding the next way to behave. When I meet one of my friends, for example, I am recognizing a variety of experiences on site to construct the interaction. Of course, the name of my friend comes to me when I notice him in the crowd, and I search for my first words in consideration of the last time we met. In the interaction that follows, I will consider many things about him, his family, or experiences we shared in the past, for example, to facilitate conversation with him. This is not limited to our encounters with others. Valsiner (2007) gives the example of saying to oneself "I like this" when observing a painting (p. 29). It is also an example of how we find out the meaning of our affective experiences and control our attitudes towards them. Thus, we relate to ourselves through signs, as semiotic cultural psychology has indicated (Valsiner, 2007). From this point of departure, I inquire throughout this monograph into the process of how signs function in the self-construction processes.

A variety of signs with social and cultural backgrounds are at work in these processes. Our language constitutes the semiotic processes, mainly as symbols, but iconic signs - typically an image of an object and an index that "enforces our attention to an object" (Valsiner, 2007, p. 42) - are also working in our minds. However, the most important point here is not such a categorized understanding of signs, as they often work in hybrid ways (Valsiner, 2007), but their function to create meaning for the future, if they are used to describe experiences in the past. Valsiner (2007) discussed this function as follows:

Each meaning, or sign, that is in use during the infinitely small time "window" we conveniently call "the present," is a semiotic mediating device that extends from the past to the possible, anticipated (but not knowable) future. The promoter role of these signs is a feedforward function: they set up the range of possible meaning boundaries for the unforeseeable, yet anticipated, future experiences with the world. The person is constantly creating meaning ahead of the time when it might be needed (...) (p. 58) 
Many researchers of psychology have focused on the meaning we construct retrospectively concerning objectively important events from the macro perspective, through established summary categorizations of life experiences. For example, the categories "meaning of my job," "a serious illness," and "unforgettable" or "traumatic" experiences are all categories of some outcome of self-reflection. They ask participants to narrate their experiences and the processes are considered the meaning construction. These discussions also introduce the concept of the self both as an agent in constructing meaning and as the representation constructed through the process.

What we find in our ordinary lives is different from such a specific, long-term way of understanding but it has the same characteristics; that is, we meet something, find the meaning of it through the use of signs to achieve distance from the experience, and then act in relation to that meaning. The excerpt of conversation I introduced at the beginning of this chapter also exemplifies this process. It is a very short interchange and does not describe the events in detail. Additionally, it is not a meaning construction concerning the here and now but rather recounts what happened in the past. However, in the flow of interaction, the child and the mother are actively creating an image of themselves and their relationship, and this work functions for the next moment of interaction, as we will see in the analysis of the episodes of conversation. Thus, who we are in relationships and in environments becomes clear in such a process of semiotically mediated meaning construction, and the following discussion is premised on this presupposition concerning our interactions and ourselves.

\section{How Interaction Develops to Describe a Child: A Foundation of the Emerging Self}

The make-up of the interaction in which we find children's meaning construction is different from the one we find in psychological research. In ordinary research, we are used to asking study participants questions expecting some statements about themselves; that is, queries in questionnaires or probes in semi-structured interviews that function as the starting point for some clarification concerning themselves. Conversely, the meaning construction we observe in real life develops in a series of interactions. For example, the episode of conversation I presented at the beginning of this chapter is extracted from a longitudinal recording of the conversation. As I describe in the forthcoming chapter, recordings were made during their car ride, mainly while returning home from the nursery Mina attended (hoikuen ${ }^{1}$ in Japanese),

\footnotetext{
${ }^{1}$ In Japan, when the recordings shown in this monograph were made, there were two types of institutions for young children before elementary school: yochien (translated as kindergarten) and hoikuen (or hoikusho) (translated as nursery or child care center). I use the Japanese expressions. On the basis of family background and local government policy, the majority of children were enrolled in either of these institutions. Currently, the Japanese government is promoting gradual integration of these two types of institution, introducing a third type of institution that combines the roles of the two preceding systems.
} 
and the transcript of the recorded interaction clarifies that this exchange is preceded by the child Mina spotting a bus stopping on the street near her home (Excerpt 1.1). ${ }^{2}$

Excerpt 1.1 (original Japanese is in Komatsu (2002))

$1 \mathrm{Mi}:$ Ah, bus!

2 Mo: Yeah, it's a bus.

3 Mi: In Mina's home.

4 Mo: Yes ... Let's turn in the corner over there. (Yes) It's not Mina's home, (1 s) cause [it's] a road. $(1 \mathrm{~s})$.

5 Mi: Isn't it Mina's home? (1 s).

6 Mo: Not [our] home, is it?

7 Mi: [It is] near Mina's home, isn't it? Why [is it] stopping here?

8 Mo: Yeah, cause the road is wider there, (Yes) (1 s) there's maybe someone getting off [the bus there].

9 Mi: Yeah so [I think].

10 Mo: [They] went to a trip. (1 s) Going out somewhere.

11 Mi: Trip means going somewhere. (3 s) xx [Inaudible].

12 Mo: A large-sized bus. (1 s) With the same pattern as the bus [they] hired at hoikuen. (1 s) [Do you] remember? Mina.

13 Mi: [I] remember, the zoo and the playland were connected.

14 Mo: Um, yeah, yeah, it was Musashi Zoo Park... Oh no, sorry, Kitano Zoo. (Yes) Where [we] visited this year? (Yes) Kitano Zoo. [I'm] sorry. (1 s).

15 Mi: And where [we] visited with Akane is?

16 Mo: Kitano Zoo. (1 s).

17 Mi: And where [we] visited long ago, when [I was] a baby?

18 Mo: When [you were] a baby, Umeno Park.

19 Mi: Yeah, right. (1 s) Was Mina cute as a baby?

20 Mo: So cute.

Mina is $4 / 6$ years old. The names of persons and places are pseudonyms. $\mathrm{Mi}=\mathrm{Mina} ; \mathrm{Mo}=$ mother; ()$=$ short answer and duration of silence (approx. figure); [ ] = contextual and additional information including pronouns omitted in conversation; $\ldots=$ short pause.

In this example, one of the basic characteristics of meaning construction is its development through the flow of interaction. Concretely, the description of Mina in babyhood as a "cute" girl is not achieved as a question and answer pair, as we saw in the beginning, but from a series of interactions that include a variety of topics. A bus on the street leads to the mother's question concerning a bus and their visit to a zoo (line 12),

\footnotetext{
${ }^{2}$ The excerpts included in this chapter are from longitudinal recordings of conversations between a young girl, Mina, and her mother, who lived in a rural area of Japan (about $80 \mathrm{~km}$ from the center of Tokyo) (Komatsu, 2006). The recordings were made during their car rides, usually on the way back home from hoikuen, as well as some other instances of recordings occurring on their way to supermarkets or the hospital. Mina's age was between 4 years 4 months and 5 years 8 months when the recordings were made, and total recording time was $34 \mathrm{~h}$ over 153 days of observation. Translation from original Japanese into English was made by the author. For further detail of the recordings and translation, see Chap. 3.
} 
after some explanations to correct Mina's understanding of word usage (lines 3-11). From this question, they talk over their visit to some zoos (lines 13-18). Mina's question concerning herself as a baby is an extension of these exchanges. Although it is difficult to describe everything in the recordings of conversation and ordinary conversations often involve fluctuations, we must grasp the interaction with a wider perspective to understand the process and the result of meaning construction.

This example also illustrates that the meaning construction is embedded in the contexts we live in. The starting point of the episode-Mina's witnessing a bus on the street-suggests at least some of our meaning construction comes from accidental encounters when we move around our surroundings. However, determining the specific elements in our environments that enable us to start the interaction is difficult. A bus can work as a starting point of a talk about the past, but it does not always inspire the same kind of talk. In other words, it just happened to be the cause of interaction in this instance. Thus, what is essential is the composition of our daily lives that enables us to encounter a variety of objects that have a potential to start our meaning construction.

Another aspect of interaction we must consider is that it constructs our relationships for the future. When a child asks her mother if she was cute, what she expects is not a correct and precise description of her babyhood but rather a feeling of an intimate and warm relationship with her mother. Although difficult to explain by reference to specific words or utterances in their conversation, this is also an aspect of who Mina was in relation to her mother, and it creates a mood or an atmosphere that canalizes the interaction afterwards. Thus, the self we can observe in meaning construction is not limited to what was described, but also includes what was brought about as the result of relational work.

\section{A Need for a New Perspective for Looking at the Self in Interaction}

The characteristics of meaning construction discussed above do not fit with the framework of psychological research that relies on objectivity and reproducibility in its understanding of human mind. The interaction depends on context and starts whimsically, and these characteristics make it hard to replicate. However, considering the irreversible nature of time, all psychological phenomena are essentially onetime events; we find (or even construct) the resemblance between two independent events. Thus, what we must pursue for the generalization of findings is not reproducibility but rather the construction of a theoretical framework that fits with the diverse meaning constructions in which we engage in our lives.

In relation to this one-time nature of the episodes of conversation, I must point out that existing psychological inquiries were not concerned with the reasons why children talk about their experiences. In many studies that analyzed conversations concerning children's experiences, researchers just asked children and their parents to talk about topics congruent with some academic standards set by the researchers 
(e.g., Haden, Haine, \& Fivush, 1997). This is an attempt to control the settings of interaction to argue for the reproducibility and generalizability of their findings. However, if we attempt to construct a framework that properly explains our meaning construction embedded in contexts, observation of what happens in natural settings is an important requirement for investigation. In other words, we must wait for the occurrence of meaning construction.

The relational work achieved in the conversations is also difficult to describe or categorize with objective standards. The intimate relationship between a young girl and her mother both mentioning the girl's cuteness is what we feel from the series of their meaning construction. However, what we understand from these interactions is not necessarily congruent with children's subjective experiences; we construct this relational effect, by becoming a pseudo-participant in the conversation through reading the transcript and employing our imagination. This requires us to focus on our work of understanding in inspecting the data, rather than simply considering that what we find is objective and self-evident.

It is also related to a need to have a wider view of interaction to understand the process in which who the child is (or was) becomes clear in meaning construction. What is achieved in an episode of interaction is not reducible to the effect of a specific word or utterance. However, in the analysis, the rambles within an interaction that are the part of whole processes are often considered noise that hides an elementary aspect of how we describe ourselves.

These discussions lead to the consideration that we need a theoretical framework to investigate children's meaning construction and their selves emerging in the process that differs from existing approaches to understanding what children's selves are. In concrete terms, a new perspective must include following orientations:

1. Looking at the process of meaning construction achieved through the continual dynamics that language or signs provide, rather than breaking down the interaction into units of words or turns and then aggregating them by several categories.

2. Considering the position of researchers or observers who investigate the process, by imaginarily participating in the interaction and finding what is achieved throughout the process of meaning construction, rather than relying on a concept of objectivity that presupposes what is happening is entirely self-evident to everyone.

3. Approving the one-time-only nature of our meaning construction, including an exploration of their whimsical occurrences, rather than emphasizing the generalization of findings through reproducibility.

In my discussion that follows, I analyze the recordings of mother-child conversations and children's writings about their experiences to understand how we figure out children's selves in meaning construction, based on the perspective I have described above. In the next section, as a starting point for this theoretical inquiry, I introduce an example that typically shows a child's self emerging through meaning construction. 


\section{Meaning Construction and an Emergence of the Self in Natural Interaction}

When we discuss the self, others often play important roles as, for example, counterparts or opponents to clarify the self in relationships. As I will discuss later in Chaps. 3 and 4, the inquiry here also focuses on how others work in the process through which we find the selves of children. From the corpus of mother-child conversation from which Excerpt 1.1 is derived, here I introduce another episode in which they talk about Mina's experiences at hoikuen. The topic of the excerpt below is about who plays what in their "theater performance" at hoikuen.

\section{Excerpt 1.2}

(Komatsu, 2010, p. 215, Excerpt 1, cited with minor modifications, original Japanese in Komatsu (2006))

1 Mo: What is Saito Taku [Mina's friend, boy] (yes) going to play in the theater performance? (1 s).

2 Mi: A bat. (2 s) And Mina [I play] a rabbit.

3 Mo: In the dance by the rabbits? The bat? (1 s) [Does he appear in] Another dance?

$4 \mathrm{Mi}$ : After the bats, (uh hum) then maybe rabbits, (hmm) bunny rabbits.

5 Mo: Mimi, the bunny ... Oops [I guess I was] wrong, snow rabbits!

6 Mi: Mina, the snow rabbit xx [inaudible].

7 Mo: Mina is [You are] a moon rabbit, aren't you? (Oh, [you are] right) A yellow rabbit, aren't you?

8 Mi: [I'm] Not a snow rabbit. (1 s) xx [inaudible]?

9 Mo: A flower rabbit. (Wrong) Mina, the moon rabbit.

10 Mi: That's right. Sayuri [Mina's friend, girl] and Sada Miki [Mina's friend, girl] play flower rabbits, don't they? (yes) Iiyama Mina and Sanae [Mina's friend, girl] are, well, moon rabbits, two moon rabbits and (yes) the white rabbit is, well, Tano (1 s) Tanokura (yes) Tano ... Tanokura, yeah, Tanokura Nagisa [Mina's friend, girl].

11 Mo: Tanokura Nagisa.

12 Mi: And then, Matsuzaka Aika [Mina's friend, girl] (yes) Machida Mina, [Mina's friend, girl] (yes) [you] see?

13 Mo: Yes, [I] see.

$14 \mathrm{Mi}$ : Three girls do that together, right?

15 Mo: Yes, but Mina [you] play in two, don't you?

16 Mi: Yes, and also Sayuri [plays] in two. (Yes) And Matsuzaka Aika [plays] in th, three. (Yes) (3 s) Three girls do (yes) that together, right? (2 s) Machida Mina ( $1 \mathrm{~s})$ is ... one [meaning 'first'] ... see? (1 s) And Sayuri is two ['second']. Mina is three ['third']. That's the way [you] memorize, right?

17 Mo: Yes. 
Although the interaction begins with the mother's question about one of Mina's friends (Saito Taku), the first half of the interaction (lines 1-9) centers on "who Mina was" in relation to the roles she played. After clarifying the relationship between "bats" and "rabbits," they introduce a variety of rabbits appearing in the performance. Mina attempts to attach the roles to herself arbitrarily (line 6), and her mother corrects her (line 7). Following this, the mother introduces another type of rabbit (line 9). Although the role Mina plays is unclear, here Mina and her mother construct a list of roles through this interaction. Based on this list or frame, in the latter half of the interaction (lines 10-18) Mina begins to describe who plays what. In this interaction, "rabbits" reappear with Mina's friends and the child and her mother discuss the arrangements for the performance. This is also a clarification of Mina's position in the group of young girls.

The description above shows that $I$ found Mina and her mother constructing and elaborating a configuration of children that also clarifies who Mina was, based on the roles they play. Here I use the word "configuration" because the transcript enables us to construct one unified figure that describes both Mina and her friends within relationships. It is not reducible to any of the turns they took in conversation but instead appears from the whole of the episode. In this configuration, Mina is clearly shown as a member of a group of young girls who are similar in their roles but different as people (see Chap. 2 for further discussion).

As I discussed in the previous section, my understanding here is not the same as what the mother and her daughter felt in this conversation, but rather my version of understanding who Mina was. For example, the names of Mina's friends have different effects for meaning construction for me and for them. Because of this, what we find in this example must be described with concepts that reflect the relational nature of interaction and meaning, not the objective abilities or dispositions of the study participants.

\section{What Works for Our Meaning Construction: Focusing on Two Aspects of Interaction}

After introducing an example that presents the figure of a child through meaning construction, the next step is an inspection of the foundations at work in our understanding of it. For this understanding, I will point out two types of discursive acts working here to clarify who Mina was in relation to others.

First, Mina locates herself in an array of same-aged peers and the roles they play. In the first half of the conversational episode, Mina and her mother introduce several "rabbits." This was done somewhat vaguely but in the latter half, the set of roles works well for Mina to establish her position in relation to many of her friends who play different roles in the performance. Here, the set of roles and the listing of friends work as an enumeration: a discursive act that "evokes a homogeneous referential ensemble to which the enumerated constituents refer" (Dubois \& Sankoff, 2001, p. 285). For observers, and possibly for Mina and her mother, the descriptions of other "rabbits" clarify the relationship in which Mina becomes 
positioned. Looking at the episode of their zoo visit in Excerpt 1.1, which was observed about 2 months after Excerpt 1.2, Mina was also trying to enumerate the places she visited, though it is not clear as in Excerpt 1.2.

Second, in accomplishing this discursive act, Mina and her mother are taking their positions in relation to each other. In the first part of the excerpt, the mother asks several questions concerning her daughter's experiences and also corrects her speech. Here, the conversation heavily relies on the mother's scaffolding to maintain the interaction and clarify the topic. In the latter half, Mina takes a position to teach her mother about her experiences. Mina sometimes confirms her mother's understanding (see lines 12-17) as teachers do to their pupils, though this is still dependent on her mother's taking the role of pupil. It is not as distinctive or strategic as the original discussion concerning positioning (Harré \& van Langenhove 1999) presupposed. However, this is interpretable as an act of positioning in this local context, as "all conversations always involve some sort of positioning" (Harré \& van Langenhove 1999, p. 29). This sort of positioning is less clear in Excerpt 1.1. Yet, as I pointed out, Mina's confirming that she was a "cute baby" can be understood as constructing an intimate relationship with her mother. Thus, the child is clarifying herself in relation to her mother, the partner in conversation.

These two aspects of one excerpt interact to clarify the young girl's self, or who Mina was, in relation to others: i.e., her friends appearing in the conversation and her mother as a partner in the interaction. This explanation relies on the concepts developed in research on discourse analysis and doesn't guarantee that the description of Mina observed here is particularly important for her, or that it reflects her stable internal figure of herself, if there is such an internal psychological existence. However, it does indicate how they constructed the interaction to present a configuration to us.

In addition, and as the most important aspect of this framework, what is not included in this discussion of positioning and enumeration is our active orientation that merges them into one integrated presentation of Mina. Although the discussions in the discourse analysis are conscious about the relationship between the text and its effects, they focus on the relativistic nature of their understanding and their position in political or academic contexts (see Parker, 2015). In other words, they do not focus on the process of how signs work to present what we understand in the episode as a whole. In the next chapter, I approach what occurs in who reads the text, considering theories that focused on the function of signs in human perception, and introduce the analyses and discussions I will undertake.

Open Access This chapter is licensed under the terms of the Creative Commons Attribution 4.0 International License (http://creativecommons.org/licenses/by/4.0/), which permits use, sharing, adaptation, distribution and reproduction in any medium or format, as long as you give appropriate credit to the original author(s) and the source, provide a link to the Creative Commons license and indicate if changes were made.

The images or other third party material in this chapter are included in the chapter's Creative Commons license, unless indicated otherwise in a credit line to the material. If material is not included in the chapter's Creative Commons license and your intended use is not permitted by statutory regulation or exceeds the permitted use, you will need to obtain permission directly from the copyright holder. 